\title{
Po/So PHASES: PROPAGATION VELOCITY ACROSS A 1,500-km-LONG, DEEP OCEAN HYDROPHONE ARRAY
}

\author{
Daniel Alvin WALKer and Charles Stoddard MCCREERY \\ Hawaii Institute of Geophysics, 2525 Correa Road, \\ Honolulu, Hawaii 96822, U.S.A.
}

(Received September 30, 1986; Revised May 18, 1987)

\begin{abstract}
Po/So phases from numerous earthquakes along the margin of the Northwestern Pacific Basin were successfully recorded by a 1,500-km-long ocean bottom hydrophone $(\mathrm{OBH})$ array deployed for two months near Wake Island. Data from ten shallow-focus $(<100 \mathrm{~km})$ events at $20^{\circ}(2,200 \mathrm{~km})$ to $34^{\circ}(3,800 \mathrm{~km})$ epicentral distance were used to compute propagation velocities across the array for the onsets of Po and So. The values found are $7.96 \pm 0.05 \mathrm{~km} / \mathrm{s}$ for $P o$ and $4.58 \pm 0.06 \mathrm{~km} / \mathrm{s}$ for So. Travel-time intercepts associated with these velocities are, respectively, $-7.21 \pm 2.40 \mathrm{~s}$ and $-12.84 \pm 7.61 \mathrm{~s}$. These velocities are significantly lower than those previously reported for the Northwestern Pacific using single station data. Although the low velocities and negative intercepts could simply be the result of bias in the data, they might also be due to the effects of azimuthal anisotropy along travel paths, or to increasing propagation velocity with lithospheric age, or to a different mode of propagation near the source.
\end{abstract}

\section{Introduction}

Late in the summer of 1981, the Hawaii Institute of Geophysics (HIG) deployed a 1,500-km-long linear array of twelve ocean bottom hydrophones (OBH's) near Wake Island (Fig. 1). Half of the instruments began recording on 12 August and ended on 23 September. The remaining half started on 3 September and ended on 15 October. The total recording time was about 65 days, and all twelve instruments were in operation from 3 September through 23 September. Of the twelve OBH's deployed, ten were recovered, and nine of these had quality data throughout their operational period. Monitored concurrently were three bottom hydrophones of the Wake Island Array (WIA), a 40-km array of hydrophones located near, and cabled directly to, Wake Island. WIA data were used in the study of first arrivals and were considered to be part of the OBH array data. All of the $\mathrm{OBH}$ and WIA instruments were in ocean depths between $5,265 \mathrm{~m}$ and $5,657 \mathrm{~m}$ (Table 1). Of more than 130 events identified from seismic phases in the recordings, 108 were located by the National Earthquake Information Service (NEIS; Table 2 


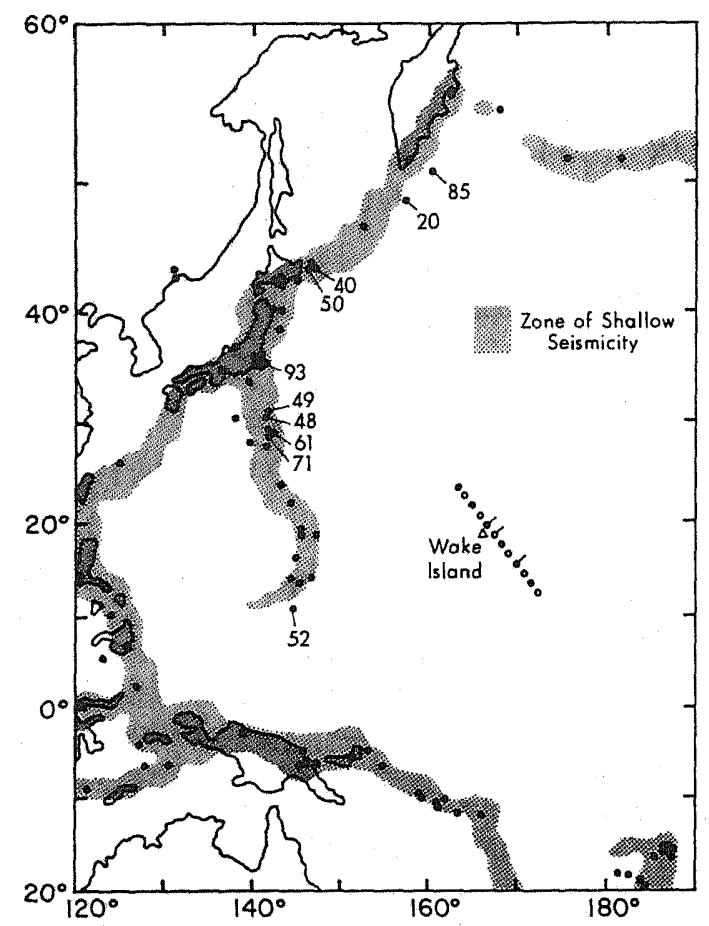

Fig. 1. Map showing OBH locations and epicenters of earthquakes recorded by the array (see Tables 1 and 2). Instruments operating from 12 August through 23 September are indicated by open circles. Those operating from 3 September through 15 October are indicated by closed circles. Three instruments that did not work properly are flagged. Event numbers (from Table 2) are indicated for epicenters of events specifically used in this study. Bottom hydrophones of WIA are at the approximate position of $\mathrm{OBH} 4$.

Table 1. Hydrophone coordinates and depths.

\begin{tabular}{cccc}
\hline Hydrophone & $\begin{array}{c}\text { Latitude } \\
(\mathrm{N})\end{array}$ & $\begin{array}{c}\text { Longitude } \\
(\mathrm{E})\end{array}$ & $\begin{array}{c}\text { Water depth } \\
(\mathrm{m})\end{array}$ \\
\hline OBH 1 & 23.18 & 163.81 & 5,657 \\
OBH 2 & 22.10 & 164.80 & 5,265 \\
OBH 3 & 21.28 & 165.54 & 5,600 \\
OBH 4 & 20.23 & 166.47 & 5,495 \\
OBH 7 & 17.25 & 169.03 & 5,445 \\
OBH 8 & 16.41 & 169.72 & 5,450 \\
OBH 10 & 14.52 & 171.28 & 5,635 \\
OBH 11 & 13.37 & 172.19 & 5,600 \\
OBH 12 & 12.55 & 172.79 & 5,580 \\
WIA 74 & 20.60 & 166.50 & 5,400 \\
\hline
\end{tabular}


Table 2. Events recorded by the OBH array (Data from NEIS Monthly Lists).

\begin{tabular}{|c|c|c|c|c|c|c|c|c|c|c|}
\hline No. & Dat & & Time & Location & $h$ & $m$ & $M$ & $n$ & Po & So \\
\hline 1 & Aug. & 12 & $22: 35$ & Solomon Is. & 33 & 4.9 & - & 3 & - & - \\
\hline 2 & & 13 & $02: 57$ & Tonga Is. & 191 & 5.4 & - & 3 & - & - \\
\hline 3 & & 14 & $05: 42$ & Volcano Is. & 33 & 4.7 & - & 3 & - & - \\
\hline 4 & & 14 & $06: 24$ & Molucca Passage & 38 & 5.5 & 5.3 & 1 & - & - \\
\hline 5 & & 14 & $09: 05$ & Honshu, Japan & 58 & - & - & 2 & - & - \\
\hline 6 & & 15 & $10: 30$ & Alaska & 53 & 5.1 & - & 2 & - & - \\
\hline 7 & & 15 & $19: 53$ & Philippine Is. & 152 & 4.8 & - & 1 & - & - \\
\hline 8 & & 16 & $23: 54$ & Kuril Is. & 33 & 5.6 & 5.0 & 3 & - & - \\
\hline 9 & & 17 & $02: 17$ & West Irian & 34 & 5.7 & 5.8 & 3 & - & - \\
\hline 10 & & 17 & $17: 07$ & Fiji Is. & 383 & 5.5 & - & 2 & - & - \\
\hline 11 & & 18 & $05: 29$ & Banda Sea & 34 & 5.1 & 4.8 & 1 & - & - \\
\hline 12 & & 19 & $01: 41$ & Kermadec Is. & 185 & 5.1 & - & 1 & - & - \\
\hline 13 & & 19 & 03:01 & Fiji Is. & 507 & 4.8 & - & 1 & - & - \\
\hline 14 & & 19 & $06: 06$ & Loyalty Is. & 25 & 5.6 & 4.9 & 1 & - & - \\
\hline 15 & & 20 & $02: 19$ & Santa Cruz Is. & 71 & 5.0 & - & 3 & - & - \\
\hline 16 & & 20 & $12: 53$ & Mariana Is. & 193 & 3.8 & - & 4 & - & - \\
\hline 17 & & 20 & $15: 10$ & Kermadec Is. & 347 & 4.9 & - & 1 & - & - \\
\hline 18 & & 21 & $14: 29$ & Bonin Is. & 509 & 4.6 & - & 1 & - & - \\
\hline 19 & & 23 & $01: 59$ & Loyalty Is. & 100 & 5.8 & - & 1 & - & - \\
\hline 20 & & 23 & $12: 00$ & Kuril Is. & 40 & 6.0 & 5.8 & 4 & 3 & 3 \\
\hline 21 & & 24 & $15: 46$ & Aleutian Is. & 56 & 5.2 & - & 2 & - & - \\
\hline 22 & & 25 & $06: 5.6$ & Honshu, Japan & 325 & 4.8 & - & 4 & - & - \\
\hline 23 & & 25 & $07: 16$ & Tonga Is. & 33 & 5.9 & 5.7 & 1 & - & 一 \\
\hline 24 & & 25 & $07: 22$ & Tonga Is. & 433 & 5.7 & - & 1 & - & - \\
\hline 25 & & 25 & $20: 07$ & Mariana Is. & 33 & 4.9 & 4.4 & 1 & - & - \\
\hline 26 & & 26 & $04: 51$ & Mariana Is. & 40 & 5.2 & 5.1 & 5 & - & - \\
\hline 27 & & 26 & $16: 32$ & New Britain & 74 & 5.7 & - & 6 & - & - \\
\hline 28 & & 26 & $18: 56$ & Honshu, Japan & 230 & 4.4 & - & 3 & - & - \\
\hline 29 & & 28 & 09:04 & Alaska & 71 & 5.1 & - & 3 & - & - \\
\hline 30 & & 30 & $11: 36$ & Fiji Is. & 609 & 5.4 & - & 6 & - & - \\
\hline 31 & & 31 & $06: 14$ & Komandorsky Is. & 33 & 4.7 & 3.8 & 1 & - & - \\
\hline 32 & Sept. & 1 & $07: 23$ & Tonga Is. & 33 & 5.8 & 5.7 & 4 & - & - \\
\hline 33 & & 1 & $09: 29$ & Samoa Is. & 25 & 7.0 & 7.7 & 6 & - & - \\
\hline 34 & & 1 & $18: 38$ & Tonga Is. & 33 & 5.7 & 5.3 & 3 & - & - \\
\hline 35 & & 1 & $23: 55$ & Tonga Is. & 33 & 5.6 & 5.4 & 3 & - & - \\
\hline 36 & & 2 & $08: 44$ & Samoa Is. & 33 & 5.3 & 5.5 & 1 & - & - \\
\hline 37 & & 2 & $09: 24$ & Honshu, Japan & 58 & 5.5 & - & 2 & - & 一 \\
\hline 38 & & 3 & $03: 59$ & Hokkaido, Japan & 52 & 4.7 & - & 4 & - & - \\
\hline 39 & & 3 & $04: 29$ & Philippine Is. & 93 & 5.8 & - & 4 & - & - \\
\hline 40 & & 3 & $05: 35$ & Kuril Is. & 45 & 6.6 & 6.6 & 10 & 6 & 6 \\
\hline 41 & & 3 & $19: 39$ & Honshu, Japan & 44 & 5.6 & 5.4 & 4 & - & 一 \\
\hline 42 & & 3 & $19: 44$ & New Guinea & 136 & 4.8 & - & 5 & - & 一 \\
\hline 43 & & 4 & $11: 15$ & Philippine Is. & 645 & 6.0 & - & 10 & - & - \\
\hline 44 & & 4 & $23: 44$ & Solomon Is. & 38 & 5.4 & 5.3 & 9 & - & - \\
\hline 45 & & 6 & $11: 02$ & Loyalty Is. & 31 & 5.9 & 6.2 & 1 & - & - \\
\hline 46 & & 7 & $15: 11$ & Fiji Is. & 231 & 5.2 & - & 3 & - & - \\
\hline 47 & & 7 & $16: 20$ & Honshu, Japan & 440 & 4.9 & - & 3 & 一 & - \\
\hline 48 & & 7 & $19: 06$ & Honshu, Japan & 33 & 5.8 & 5.5 & 7 & 6 & 5 \\
\hline 49 & & 7 & $20: 07$ & Honshu, Japan & 29 & 5.1 & 4.7 & 7 & 5 & 4 \\
\hline
\end{tabular}


Table 2. (continued)

\begin{tabular}{|c|c|c|c|c|c|c|c|c|c|c|}
\hline No. & \multicolumn{2}{|c|}{ Date } & Time & Location & $h$ & $m$ & $M$ & $n$ & Po & So \\
\hline 50 & Sept. & 8 & $19: 26$ & Kurils Is, & 46 & 5.7 & 5.4 & 5 & - & 3 \\
\hline 51 & & 10 & $03: 29$ & Solomon Is. & 110 & 4.9 & - & 3 & - & - \\
\hline 52 & & 10 & $23: 21$ & Mariana Is. & 13 & 5.6 & 5.2 & 10 & 5 & - \\
\hline 53 & & 11 & $08: 33$ & Fiji Is. & 554 & 5.2 & - & 5 & - & - \\
\hline 54 & & 12 & $03: 40$ & Fiji Is. & 302 & 5.2 & - & 3 & - & - \\
\hline 55 & & 12 & $07: 15$ & Kashmir & 33 & 6.2 & 5.9 & 3 & - & - \\
\hline 56 & & 12 & $14: 51$ & Hokkaido, Japan & 111 & 4.9 & - & 7 & - & - \\
\hline 57 & & 12 & $16: 14$ & Bonin Is. & 33 & 4.6 & - & 2 & - & - \\
\hline 58 & & 13 & $01: 20$ & Honshu, Japan & 39 & 4.8 & 4.8 & 4 & - & - \\
\hline 59 & & 13 & $02: 17$ & Eastern Kazakh & 0 & 6.0 & 4.5 & 4 & - & - \\
\hline 60 & & 13 & $20: 24$ & Honshu, Japan & 87 & 4.9 & - & 3 & - & 一 \\
\hline 61 & & 14 & $15: 08$ & Honshu, Japan & 33 & 5.4 & 5.0 & 4 & 4 & - \\
\hline 62 & & 15 & $14: 12$ & Banda Sea & 102 & 5.9 & - & 2 & - & - \\
\hline 63 & & 15 & $20: 43$ & Taiwan & 167 & 4.9 & - & 3 & - & - \\
\hline 64 & & 17 & $06: 19$ & Banda Sea & 33 & 5.7 & 5.8 & 1 & 一 & 一 \\
\hline 65 & & 17 & $08: 23$ & Loyalty Is. & 30 & 5.7 & 6.6 & 2 & - & 一 \\
\hline 66 & & 17 & $12: 42$ & Fiji Is. & 356 & 5.2 & - & 10 & - & - \\
\hline 67 & & 17 & $21: 12$ & Kamchatka & 33 & 4.9 & 3.9 & 2 & - & - \\
\hline 68 & & 19 & $07: 27$ & China & 561 & 4.4 & - & 3 & - & - \\
\hline 69 & & 20 & $04: 39$ & Honshu, Japan & 33 & 4.4 & - & 2 & - & - \\
\hline 70 & & 22 & $06: 55$ & Mariana Is. & 33 & 4.2 & - & 6 & - & 一 \\
\hline 71 & & 24 & $17: 20$ & Bonin Is. & 33 & 5.7 & 5.3 & 5 & 3 & 2 \\
\hline 72 & & 25 & $03: 25$ & New Guinea & 116 & 4.8 & - & 1 & - & 一 \\
\hline 73 & & 25 & $10: 21$ & Bonin Is. & 33 & 4.4 & - & 2 & - & - \\
\hline 74 & & 25 & $14: 30$ & Kermadec Is. & 45 & 5.9 & 5.9 & 5 & - & - \\
\hline 75 & & 25 & $15: 01$ & Honshu, Japan & 25 & 5.5 & 6.1 & 2 & - & - \\
\hline 76 & & 28 & $03: 36$ & Honshu, Japan & 31 & 5.5 & 5.3 & 5 & - & - \\
\hline 77 & & 28 & $17: 56$ & Kermadec Is. & 323 & 6.0 & - & 5 & - & - \\
\hline 78 & & 29 & $23: 02$ & Tonga Is. & 226 & 5.1 & - & 5 & - & - \\
\hline 79 & & 30 & $07: 04$ & New Guinea & 123 & 5.4 & - & 4 & - & - \\
\hline 80 & & 30 & $23: 03$ & Pacific Ocean & 10 & 5.9 & 5.2 & 2 & - & 一 \\
\hline 81 & & 30 & $23: 37$ & Hokkaido, Japan & 52 & 4.9 & 4.9 & 2 & - & - \\
\hline 82 & Oct. & 1 & $12: 14$ & Novaya Zemiya & 0 & 5.9 & 3.8 & 4 & - & - \\
\hline 83 & & 1 & $13: 10$ & New Ireland & 85 & 5.0 & - & 2 & - & 一 \\
\hline 84 & & 1 & $16: 02$ & Kermadec Is. & 33 & 5.6 & 5.1 & 5 & - & 一 \\
\hline 85 & & 1 & $17: 04$ & Kuril Is. & 33 & 5.9 & 5.7 & 5 & 4 & 4 \\
\hline 86 & & 1 & $19: 00$ & S. Nevada & 0 & 4.9 & - & 2 & - & - \\
\hline 87 & & 2 & $05: 51$ & Savu Sea & 109 & 4.6 & - & 4 & - & - \\
\hline 88 & & 2 & $15: 13$ & Mariana Is. & 113 & 5.0 & - & 5 & - & 一 \\
\hline 89 & & 3 & $07: 21$ & Kuril Is. & 75 & 5.1 & - & 4 & - & - \\
\hline 90 & & 3 & $08: 26$ & Hokkaido, Japan & 62 & 4.4 & - & 2 & - & - \\
\hline 91 & & 3 & $16: 48$ & Philippine Is. & 238 & 5.0 & - & 2 & - & 一 \\
\hline 92 & & 4 & $00: 01$ & New Guinea & 33 & 5.9 & 6.3 & 4 & - & - \\
\hline 93 & & 4 & $04: 11$ & Honshu, Japan & 38 & 5.2 & 5.0 & 4 & - & 2 \\
\hline 94 & & 4 & $10: 18$ & Solomon Is. & 58 & 5.1 & - & 2 & - & 一 \\
\hline 95 & & 4 & $10: 27$ & Solomon Is. & 24 & 5.7 & 5.4 & 5 & - & - \\
\hline 96 & & 5 & $04: 28$ & China & 534 & 4.7 & - & 2 & - & - \\
\hline 97 & & 6 & $07: 40$ & Aleutian Is. & 23 & 5.2 & 4.3 & 3 & - & - \\
\hline 98 & & 7 & $03: 02$ & Fiji Is. & 620 & 5.8 & - & 5 & - & - \\
\hline
\end{tabular}


Table 2. (continued)

\begin{tabular}{|c|c|c|c|c|c|c|c|c|c|c|}
\hline No. & \multicolumn{2}{|c|}{ Date } & Time & Location & $h$ & $m$ & $M$ & $n$ & $P o$ & So \\
\hline 99 & Oct. & 7 & $08: 23$ & Solomon Is. & 41 & 5.8 & 5.3 & 5 & - & - \\
\hline 100 & & 7 & $15: 03$ & Samoa Is. & 33 & 4.8 & - & 2 & - & - \\
\hline 101 & & 7 & $17: 48$ & Philippine Is. & 595 & 5.3 & - & 4 & - & - \\
\hline 102 & & 9 & $12: 19$ & Solomon Is. & 50 & 6.0 & 6.4 & 5 & - & - \\
\hline 103 & & 9 & $19: 46$ & Mariana Is. & 96 & 4.7 & - & 5 & - & - \\
\hline 104 & & 11 & $00: 36$ & Minahassa Pen. & 94 & 5.6 & - & 4 & - & - \\
\hline 105 & & 13 & $15: 53$ & Kamchatka & 112 & 5.3 & - & 3 & - & - \\
\hline 106 & & 14 & $12: 29$ & Mariana Is. & 205 & 5.0 & - & 5 & - & - \\
\hline 107 & & 14 & $20: 09$ & Mariana Is. & 131 & 4.9 & - & 5 & - & - \\
\hline 108 & & 15 & $01: 47$ & Honshu, Japan & 47 & 6.0 & 5.4 & 5 & - & - \\
\hline
\end{tabular}

$h$, Event depth $(\mathrm{km}) ; m$, body-wave magnitude; $M$, surface-wave magnitude; $n$, number of instruments in array which recorded body-wave phases P, Po, or So from this event; Po, number of Po arrivals from this event used in first-arrival study; So, number of So arrivals from this event used in firstarrival study.

and Fig. 1). The primary purpose of the experiment was to acquire data of critical importance in understanding a phenomenon known as high-frequency $\mathrm{Pn} / \mathrm{Sn}$, longrange $\mathrm{Pn} / \mathrm{Sn}$, or Ph.f./Sh.f.; but referred to here as Po/So or Ocean P/Ocean S after WALKER (1982).

Po/So phases were first observed in the North Atlantic and have been found throughout the North, Western, and Central Pacific. In the Western Pacific, the seismic velocities and high-frequency character of these phases have been reported by Asada and Shimamura (1976), Shimamura and Asada (1976), Shimamura et al. (1977), WALKer (1977a, b), WALKer et al. (1978), SutTon et al. (1978), Ouchi (1981), Ouchi et al. (1983), NAGUMo et al. (1981), WALKER et al. (1983), ButLER (1986), and Cessaro and DuennebIER (1987). First-arriving Po/So energy travels with a fairly constant velocity of about 8.0 and $4.6 \mathrm{~km} / \mathrm{s}$, respectively, and peak amplitude arrivals have velocities of about 7.6 and $4.5 \mathrm{~km} / \mathrm{s}$, respectively, which are comparable to basal crustal rates. At distances of about $18^{\circ}(\simeq 2,000 \mathrm{~km})$, observed frequencies of Po and So are as high as 30 and $35 \mathrm{~Hz}$, respectively; and at distances of about $30^{\circ}(\simeq 3,300 \mathrm{~km})$, as high as 15 and $20 \mathrm{~Hz}$, respectively. The signal/noise ratios for $\mathrm{Po} / \mathrm{So}$ phases are often much greater than the ratios of corresponding normal, mantle-refracted P and S phases; and in many instances no P's or S's can be found despite the presence of very strong Po's and So's. Except for the SOFAR channel of the world's oceans, the Po/So waveguide appears to be the earth's most efficient acoustical waveguide. Also, it seems probable that the phenomenon is a dominant feature of all of the world's oceans and marginal seas-with the entire lithosphere, or large portions of it, serving as the Po/So waveguide.

Recent efforts have been made, using synthetics, to determine the mechanism of Po/So propagation (e.g., FuCHS and SCHULZ, 1976; STEPHENS and IsACKs, 1977; MENKE and Richards, 1980; SutTon and HARVEY, 1981; GetTrust and FraZER, 
1981; Sereno and OrCutt, 1985; Mallick and Frazer, 1986), although many essential characteristics of these phases are still poorly known. Data collected before the present experiment, composed almost entirely of events recorded at single stations and over an unevenly distributed range of epicentral distances, made difficult the precise determination of the travel-time curve between $0^{\circ}$ and $40^{\circ}$, as well as the attenuation of these phases as a function of frequency and distance. The high frequencies and large signal/noise ratios observed would indicate that $\mathrm{Po} / \mathrm{So}$ attenuation must be significantly smaller than that of normal, mantle-refracted $\mathrm{P}$ or $\mathrm{S}$ phases at similar distances. When a frequency-independent model for $Q$ was fit to some older Po/So data with frequencies between about 2 and $10 \mathrm{~Hz}$, the resulting $Q$ values were greater than 5,000 in most cases (WALKER et al., 1978; SUTTON et al., 1978). These values are much higher than those generally found for upper mantle travel paths from $\mathrm{P}$ and $\mathrm{S}$ data at frequencies below 2 or $3 \mathrm{~Hz}$. However, the high frequencies and large signal/noise ratios might also be due in part to a frequencydependent $Q$ combined with low noise levels at the higher frequencies (greater than $4 \mathrm{~Hz}$ ) where Po/So are most prominent. SutTon et al. (1983) found two methods for extracting a relationship between $Q$ and frequency from single-station Po/So data. They found that $Q$ was approximately proportional to frequency over the range $2-9 \mathrm{~Hz}$ and that the $Q$ of So was higher than the $Q$ of Po for any given frequency. Unfortunately, the older data (i.e., different earthquakes recorded at only single stations) make it hard to separate attenuation from other factors that influence the observed amplitudes such as magnitude, focal depth, epicentral distance, focal mechanism, and possibly azimuth.

To eliminate some of these uncertainties, an experiment was designed to record $\mathrm{Po} /$ So across a linear, 1,500-km-long array consisting of $12 \mathrm{OBH}$ 's. The data provided by such an experiment would permit determination of Po and So velocities independent of the source parameters, and thus, hopefully, would eliminate a major source of scatter and error in velocity estimates. Also, data from the experiment would facilitate a nearly direct measure of attenuation as a function of frequency and travel time (ignoring near station effects, only a spreading term would have to be assumed in order to determine the apparent $Q$ ).

The array was aimed toward northern Japan and the southernmost islands of the Kuril chain (Fig. 1). This target was chosen because of its long history of moderate-to-large earthquakes and several successful recordings of Po/So phases from this region on the hydrophone installation at Wake Island. Of the events recorded by the $\mathrm{OBH}$ array in the Marianas through Kuril portion of the circumPacific arc, the largest (a $6.6 \mathrm{mb}$; event 40 in Table 2) occurred in the target area while all of the instruments were recording.

\section{Po and So Propagation Velocities}

Analysis of $\mathrm{Po} /$ So first arrivals to determine their propagation velocity was limited to those events with focal depths of $100 \mathrm{~km}$ or less that had travel paths 


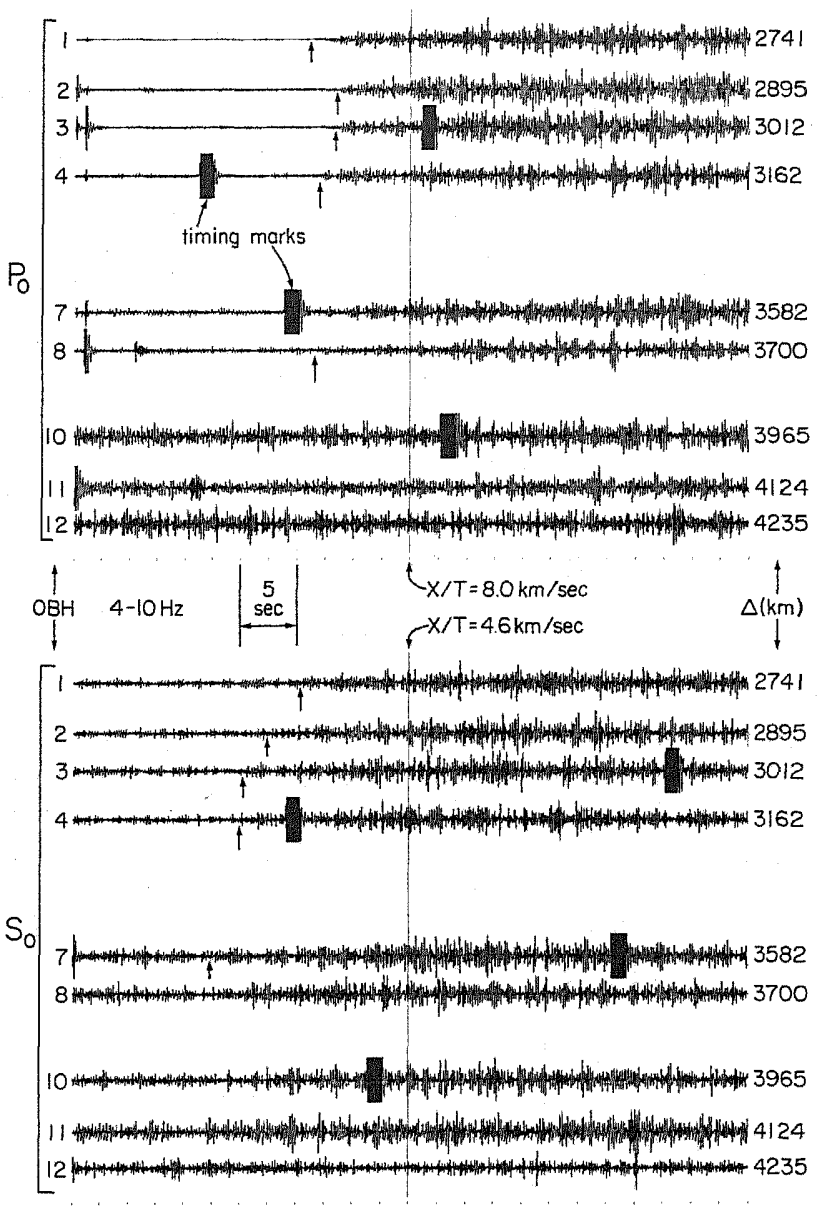

Fig. 2. Po and So first arrivals from a $6.6 \mathrm{mb}$ event in the Kuril Islands (event 40 , Table 2) shown in a reduced record-section form. The WIA hydrophone trace is not shown, but it would be at approximately the position of OBH 4. All traces were bandpass filtered between 4 and $10 \mathrm{~Hz}$. Arrows indicate positions of first arrival picks.

to the $\mathrm{OBH}$ array lying entirely within the Northwestern Pacific Basin. In addition, for each type of phase (i.e., Po or So), an event was used only if there were clear first arrivals of that phase on at least two hydrophones in the array. First arrivals were picked independently by each author, and an arrival time was used only when the picks were in approximate agreement to a few tenths of a second. A total of thirty-six Po first arrivals from eight events, and twenty-nine So arrivals from a slightly different set of eight events were analyzed (see Table 2). Figure 2 shows the set of Po and So first arrivals from the $6.6 \mathrm{mb}$. Kuril Islands event in 


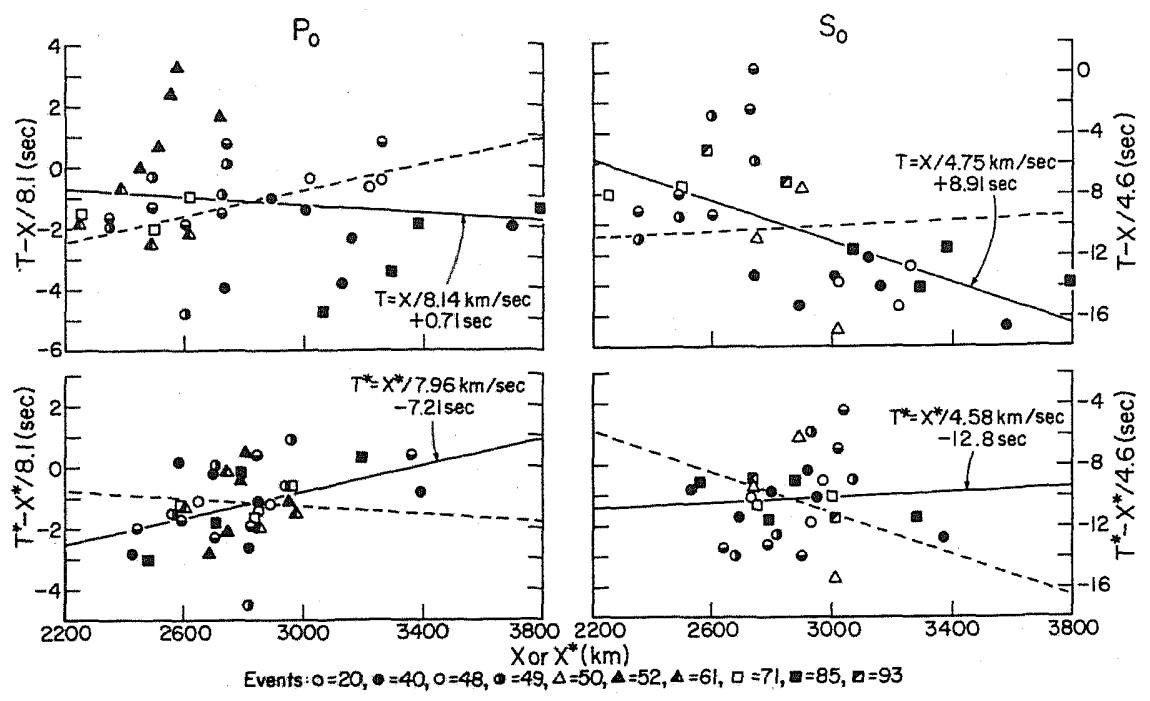

Fig. 3. Reduced travel-time plots of Po and So first arrival data. The upper half shows the raw epicentral distance, travel-time $(X, T)$ data, and the lower half shows the modified $\left(X^{*}, T^{*}\right)$ data used to compute velocities across the array. Least-squares lines (solid lines) have been fit to each set of data and their respective equations are indicated. The dashed line on each upper plot is the same as the solid line on the corresponding lower plot, and vice versa. Event numbers are those given in Table 2.

reduced record section form. Arrows indicate the actual positions of first arrival picks.

A standard approach for determining the constant propagation velocity in a waveguide from travel time data is to use least-squares linear regression directly on those data. That is, an observed travel time, $T_{i}$, is modelled as a function of its epicentral distance, $X_{i}$, by the following equation: $T_{i}=X_{i} / V+I+\varepsilon_{i}$; where $V$ is the propagation velocity, $I$ is the travel-time intercept (i.e., the travel time at zero epicentral distance), and $\varepsilon_{i}$ is the residual error of that observation. $V$ and $I$ are chosen so that the sum of the squares of all the residual errors is minimized. This is the approach that has primarily been used on the single station data (e.g., WALKER, $1977 \mathrm{~b}$ ). When this method is applied to the data of this experiment (see Fig. 3upper half), the following travel-time equations result: $T=X /(8.14 \pm 0.05 \mathrm{~km} / \mathrm{s})+$ $(0.71 \pm 2.16 \mathrm{~s})$ for $\mathrm{Po}$, and $T=X /(4.75 \pm 0.04 \mathrm{~km} / \mathrm{s})+(8.91 \pm 5.25 \mathrm{~s})$ for So.

Unfortunately, this method has certain shortcomings which can limit its usefulness. For one, it is highly dependent on knowing the epicenter and origin time precisely in order to determine each $X_{i}$ and $T_{i}$. Errors in these parameters translate directly into uncertainties in $V$ and $I$. In addition, any near source effects on the travel time that are not common to all of the events represented will also contribute to uncertainty or error in $V$ and $I$. But, differences in near source effects are to be 
expected in most data sets due to variations in focal depth, and to variations in the geometry of subduction in the source region, especially as it relates to the direction of the travel path. Also, the method assumes that the waveguide velocity is constant for all travel paths, or at least that variations in velocity are not correlated with epicentral distance. This may not be the case in the Northwestern Pacific, however, since for most previous data as well as the current $\mathrm{OBH}$ data set shorter travel paths are from earthquakes in the Marianas and Bonin Islands, while longer travel paths are more to the north from earthquakes in Japan and the Kuril Islands. Thus, any regional or azimuthal variation in the waveguide velocity can translate into additional scatter and even error in the determinations of $V$ and $I$,

Data from the OBH array, combined with a slightly different least-squares model for determining $V$ and $I$ provided the opportunity to eliminate or greatly reduce these short comings. The form of this model is: $T_{i j}+\bar{T}-\bar{T}_{i}=\left(X_{i j}+\bar{X}-\bar{X}_{i}\right) /$ $V+I+\varepsilon_{i j}$; where $T_{i j}$ and $X_{i j}$ are, respectively, the travel-time and epicentral distance from the $i$ th earthquake to the $j$ th hydrophone, $\bar{T}_{i}$ and $\bar{X}_{i}$ are, respectively, the mean travel-time and mean epicentral distance for observations of the $i$ th event, $\bar{T}$ and $\bar{X}$ are the mean travel-time and mean epicentral distance for all observations, $V$ is the propagation velocity, $I$ is the travel-time intercept, and $\varepsilon_{i j}$ is the residual error. Although the model looks complicated, if we let $T_{i j}^{*}=T_{i j}+\bar{T}-\bar{T}_{i}$ be the modified travel-time and $X_{i j}^{*}=X_{i j}+\bar{X}-\bar{X}_{i}$ be the modified epicentral distance, then the model becomes $T_{i j}^{*}=X_{i j}^{*} / V+I+\varepsilon_{i j}$-which looks very much like the old model. As before, $V$ and $I$ are found by minimizing the sum of the squares of the residual errors. This is simply a least-squares line fit to the modified data.

This model has several advantages. For one, an error in travel-time that is common to all arrivals from a given event will only affect any corresponding $T_{i j}^{*}$ to the extent that it modifies $\bar{T}$. That is because the error is cancelled out in the computation of $T_{i j}^{*}$ by subtraction of the $\bar{T}_{i}$ term. And since the $\bar{T}$ term is constant and is common to all the $T_{i j}^{*}$ terms in the analysis, errors of this type do not affect $V$, but only affect $I$. Thus, errors in travel-time that are due to errors in reported origintimes, variations in focal-depth, or variations in the subduction geometry have no effect on $V$. By a similar argument, errors in epicentral distance that are common to a given event, such as those produced by errors in the reported epicenter, also have no effect on $V$. And finally, any regional or azimuthal variations in the propagation velocity that happen to be correlated with epicentral distance will not affect $V$ in a biasing way, but will simply be averaged together. This is because the average modified travel-time, $\bar{T}_{i}^{*}$, and average modified epicentral distance, $\bar{X}_{i}^{*}$, are constant and equal to $\bar{T}$ and $\bar{X}$ for all events. Essentially, this model is designed to measure Po and So propagation velocities across the array versus measuring the average propagation velocity over a portion of the Po or So travel-time curve as the other model is designed to do.

The lower half of Fig. 3 shows reduced travel-time plots of the modified Po/So data, with corresponding least-squares lines drawn through them. The equations for these lines are: $T^{*}=X^{*} /(7.96 \pm 0.05 \mathrm{~km} / \mathrm{s})-(7.21 \pm 2.40 \mathrm{~s})$ for $\mathrm{Po}$, and $T^{*}=X^{*} /$ 
$(4.58 \pm 0.06 \mathrm{~km} / \mathrm{s})-(12.84 \pm 7.61 \mathrm{~s})$ for So. The values found for $V$ and $I$ are somewhat surprising. It is easy to see in the figure that the lines fit to these modified data are not well-suited to the unmodified data, and vice versa. In addition, these velocities are significantly lower than velocities of $8.33 \mathrm{~km} / \mathrm{s}$ for $P o$ and $4.77 \mathrm{~km} / \mathrm{s}$ for So that have previously been reported for the northwestern Pacific (WALKER, $1977 \mathrm{~b}$ ). Also, the large negative intercepts appear to be somewhat hard to explain. They do imply that the Po/So energy must be propagating at a faster rate somewhere nearer the source than where these observations were made. Before discussing further the possible implications of these results in terms of $\mathrm{Po} / \mathrm{So}$ propagation, it is worthwhile to examine the remaining sources of experimental error in the data that could be a cause of bias in these results.

\section{Sources of Error}

Possible sources of error include instrument-specific error such as $\mathrm{OBH}$ clock errors, OBH location errors, and errors caused by differences in crustal structure across the array. We estimate the magnitude of each of these types of errors to be no more than a few tenths of a second. Since the array is linear, and since all of the signals studied transversed the array in the same sense (i.e., from northwest to southeast), then any trend in these errors across the array would produce an error in $V$ (and in $I$ ). For example, at $8 \mathrm{~km} / \mathrm{s}$, a trend amounting to one second across $500 \mathrm{~km}$ of the array would produce an error in $V$ of $0.13 \mathrm{~km} / \mathrm{s}$ (and an error in $I$ of $5.7 \mathrm{~s}$ ). Similarly at $4.6 \mathrm{~km} / \mathrm{s}$, a trend amounting to one second across $500 \mathrm{~km}$ would produce an error in $V$ of $0.04 \mathrm{~km} / \mathrm{s}$ (and an error in $I$ of $5.4 \mathrm{~s}$ ). Although there is no way to measure the actual magnitude of this effect in our small data set, precisely because it is inseparable from the velocities we are trying to measure, it is important to recognize this as a source of possible bias in the results.

Another important source of error which could bias $V$ is the error in times of first-arrival picks. Both Po and So are emergent phases. Even when their coda have very large signal-to-noise ratios, their onsets often creep out of the noise. This characteristic, combined with the fact that signal-to-noise ratios decrease with increasing epicentral distance across the array, can easily produce a bias in the determination of $V$. The sense of this bias is negative; that is, its effect will reduce $V$ by some amount. When looking at the Po/So first arrivals in Fig. 2, for example, it is easy to imagine that arrivals at greater epicentral distances might be picked at a later point in their emergent onset relative to arrivals at shorter epicentral distances. The magnitude of this pick bias might be a second or more across the array, and thus could have a significant effect on $V$ and $I$, as was previously demonstrated.

Another source of error might be off-axis effects. With the exception of events 40 and 50, from the Kuril Islands, all events analyzed have Po/So signals that propagate across the array in a direction somewhat oblique to the axis of the array. Consequently, for a given event, the signal at each instrument has sampled, laterally, a slightly different part of the lithosphere. Thus, the velocity measured 
between instruments could have errors caused by lateral differences between travel paths. If there is a trend to these errors, it will produce an error in $V$.

\section{Propagation Models}

In spite of the many possible causes for error in these determinations of $V$ and $I$, it is interesting to speculate on models for Po/So propagation that could produce the apparently low propagation velocities across the array and the corresponding negative travel-time intercepts. BUTLER (1985) studied this same data set and suggested that azimuthal anisotropy in the lithosphere could explain the observations. Since the array is nearly parallel to magnetic lineations near Wake, propagation down the array could be in the slow direction, hence the relatively slow observed velocities. Furthermore, magnetic lineations in the source region near Japan and the Kuril Islands have a different orientation and are nearly perpendicular to the travel paths. Thus, the Po/So energy could propagate faster near the sourcean effect that could produce negative travel-time intercepts. Unfortunately, attempts to measure the actual level of azimuthal anisotropy from these data are inconclusive, primarily because the linear array is unsuited for such measurements. More work needs to be done to assess this phenomenon and its effects.

A second model that might explain these observations is suggested by the apparent direct relationship between Po/So propagation velocities and lithospheric age (e.g., HART and Press, 1973; MCCreEry, 1981). In the Northwestern Pacific, the age of the lithosphere is generally increasing towards the subducting edge. Thus, Po/So energy propagating towards the $\mathrm{OBH}$ array might be systematically changing its velocity from faster to slower rates along the travel path. This would produce both slower velocities across the array, and negative travel-time intercepts. It is worthwhile to note that the average propagation velocity to the array that would be necessary to achieve a zero intercept is $8.13 \mathrm{~km} / \mathrm{s}$ for Po and $4.68 \mathrm{~km} / \mathrm{s}$ for So. These values are within the range of possible effects that might be produced by an increasing velocity due to lithospheric age.

\section{Comparisons to Older Data}

Figure 4 is a plot of most of the Po/So first arrival data collected by HIG in the Northwestern Pacific Basin since 1963. Much of this data is from WALKER (1977 b). Some modifications were made to a few of those published data (i.e., 13 Po velocities and 5 So velocities) because of errors that were found in some of the original hydrophone coordinates. The formerly secret status of those hydrophone sites, and the circuitous route by which coordinates were originally obtained are the likely cause for those unfortunate errors. Recomputation of epicentral distances for the erroneous data produced two significant changes to the results of that report. First, it eliminated an apparent discontinuity in propagation velocity which had been suggested at about $30^{\circ}$ epicentral distance. Second, it lowered the Po/So 


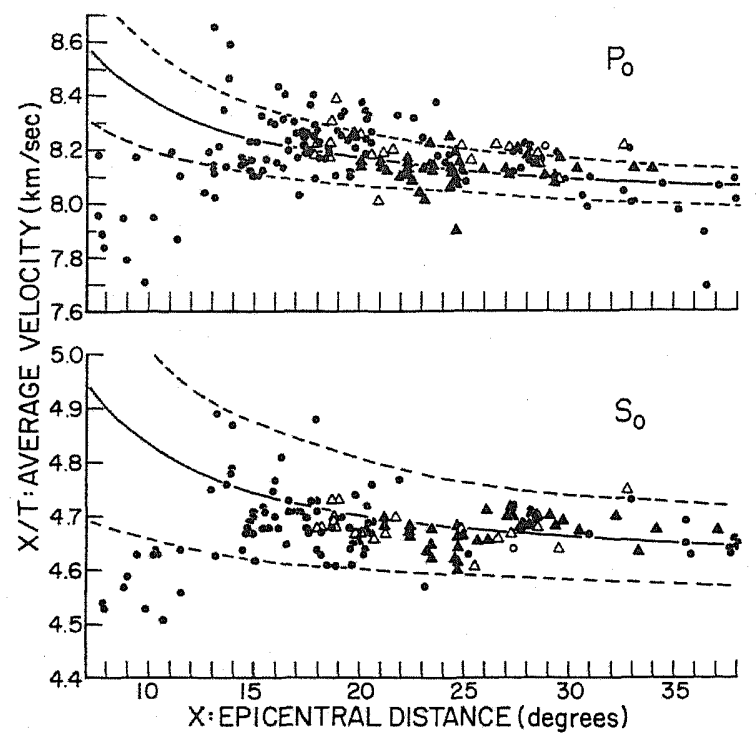

Fig. 4. Average velocity $(X / T)$ versus epicentral distance $(X)$ for Po and So with Northwestern Pacific travel paths and focal depths of $100 \mathrm{~km}$ or less. Included in this data set are island seismograph and deep ocean hydrophone data collected before the $\mathrm{OBH}$ experiment (dots), data from WIA collected between 1978 and 1980 (open triangles), and data from the OBH experiment (solid triangles). Superimposed on these data are curves representing the travel-time line computed from the modified OBH data, with plus and minus one standard deviation.

propagation velocities somewhat, a result that moved those values nearer to the values found using the modified $\mathrm{OBH}$ array data.

First arrival data are plotted in Fig. 4 as average velocity $(X / T)$ versus epicentral distance $(X)$. Superimposed on this plot are curves representing the Po and So travel-time lines computed from the modified $\mathrm{OBH}$ array data (lower half of Fig. 3), with plus and minus one standard deviation. Standard deviations were computed not only from the error in the $V$ and $I$ values of the travel-time line, but also from an additional assumed error of $10 \mathrm{~km}$ in epicentral distance and $1 \mathrm{~s}$ in origin time, since these additional types of error are present in the $X / T$ data. In spite of the fact that the travel-time lines do not fit the unmodified $\mathrm{OBH}$ array data very well, as illustrated in Fig. 3, they do seem to fit somewhat better to this larger collection of Northwestern Pacific data. The most prominent exceptions to the fit are at epicentral distances less than about $12^{\circ}$, where average velocities are much lower, and in So at distances between about $12^{\circ}$ and $27^{\circ}$, where most data fall below the curve.

The obvious discontinuity in these data at about $12^{\circ}$ epicentral distance requires explanation. It could be the manifestation of a different branch of the Po 
and So travel-time curves. The average $X / T$ for the data at less than $12^{\circ}$ is $7.96 \pm 0.16$ for Po and $4.58 \pm 0.05$ for So. Except for the standard deviations, these values are identical to the propagation velocities found across the $\mathrm{OBH}$ array. Qualitatively then, a model for these observations might be that the $\mathrm{Po} / \mathrm{So}$ first arrival energy travels entirely within the waveguide out to distances of $12^{\circ}$; but beyond $12^{\circ}$ the first arrival energy has propagated along another slightly faster path before being trapped in the waveguide. However, another explanation might simply be that these data at less than $12^{\circ}$ are incompatible with the rest, since 10 out of the 12 data points for both Po and So are from only one seismic station-Marcus Island. These data could be indicators of azimuthal anisotropy, since their associated travel paths to Marcus appear to be primarily in the slow direction based on nearby magnetic lineations. Additional data at distances near $12^{\circ}$ will be needed to resolve the questions pertaining to this apparent discontinuity.

In this regard, we note that three additional data points are available from OucHI et al. (1983) for distances less than $12^{\circ}$. These observations were acquired during an OBS experiment west of Marcus Island in June and July of 1981. The earthquake which provided the data, recorded at distances of approximately $9.4^{\circ}$, $10.5^{\circ}$, and $11.5^{\circ}$, occurred off the east coast of northern Honshu. The average velocities $(X / T)$ estimated from their reduced travel time curves are approximately $7.8 \mathrm{~km} / \mathrm{s}$. Although these values are comparable to those found at Marcus Island, additional data is still needed for distances less than $12^{\circ}$. We note that OucH et al. (1983) also provide a plausible explanation for some of the unusually high Po velocity values observed in the Western Pacific. They believe that low-frequency (i.e., $3 \mathrm{~Hz}$ ), high-velocity (i.e., $\$ 8.39 \mathrm{~km} / \mathrm{s}$ ) arrivals apparent at distances from about $9-15^{\circ}$ are probably mantle-refracted $\mathrm{P}$ phases. Furthermore, they believe that such phases could be misinterpreted as Po arrivals.

\section{Conclusions}

Data collected by a $1,500-\mathrm{km} \mathrm{OBH}$ array deployed for two months in the Northwestern Pacific Basin near Wake Island have provided some new information about the propagation of $\mathrm{Po} / \mathrm{So}$ phases. With this array, propagation velocities of first arrivals from shallow-focus $(<100 \mathrm{~km})$ events have been measured by a different and hopefully more accurate method than was previously possible with single station data. The velocities found are $7.96 \pm 0.05 \mathrm{~km} / \mathrm{s}$ and $4.58 \pm 0.06 \mathrm{~km} / \mathrm{s}$ for Po and So, respectively, measured at epicentral distances between $20^{\circ}(2,200 \mathrm{~km})$ and $34^{\circ}(3,800 \mathrm{~km})$. Associated with these propagation velocities in the linear traveltime equation are intercepts equal to $-7.21 \pm 2.40 \mathrm{~s}$ and $-12.84 \pm 7.61 \mathrm{~s}$ for Po and So, respectively. These large negative intercepts imply higher propagation velocities over some part of the travel path nearer to the source than where the data were recorded. Higher velocities might be achieved by the effects of azimuthal anisotropy in the waveguide or by increasing propagation velocity with lithospheric age. Travel times of Po/So first arrivals from older data collected by HIG since 1963, for 
shallow-focus events with Northwestern Pacific Basin travel paths greater than $12^{\circ}$ epicentral distance, are modeled reasonably well by the travel-time line reported here. However, data at epicentral distances less than $12^{\circ}$ (also collected prior to this experiment) have much lower average velocities $(X / T)$ and may follow a different Po/So travel-time branch than the one described by the $\mathrm{OBH}$ data. Additional data is needed to resolve this discontinuity at $12^{\circ}$.

Regarding attenuation, we note that the magnitude 6.6 , Kuril Island event (event 40, Table 2) is especially important. Its large magnitude and its location in the area targeted by the array produced Po/So phases that travelled down the axis of the $1,500-\mathrm{km}$ deployment line with sufficient energy to be observed with high signal/noise ratios on many of the instruments. Using this data BUTLER et al. (1987) found frequency dependent $Q$ 's for both Po and So. $Q$ values for Po ranged from about 300 at $2.5 \mathrm{~Hz}$ to 1,500 at $17.5 \mathrm{~Hz}$, and values for So ranged from about 400 at $2.5 \mathrm{~Hz}$ to 3,000 at $22.5 \mathrm{~Hz}$.

In conclusion, it is our hope that all of these results will provide meaningful constraints on modeling efforts, resulting ultimately in a better understanding of the oceanic lithosphere and the dynamics of sea-floor spreading.

This research was supported by the Office of Naval Research (code 425 GG). Funds for support of the hydrophone station at Wake Island were provided primarily by the Air Force Office of Scientific Research with supplementary support from the U.S. Arms Control and Disarmament Agency. The authors express thanks to Dave Byrne, Grant Blackinton, Bob Mitiguy, Dave Barrett, and Fred Duennebier for their help in modifying, testing, launching, and recovering the OBH's. Appreciation is also expressed to Al David and Kentron Corporation for their part in maintaining the recording station at Wake. The authors also thank George Sutton, Neil Frazer, and Rhett Butler for reviewing earlier versions of this manuscript, and Rita Pujalet for editorial assistance. Hawaii Institute of Geophysics Contribution No. 1903.

\section{REFERENCES}

ASADA, T. and H. SHMAMURA, Observations of earthquakes and explosions at the bottom of the Western Pacific: Structure of the oceanic lithosphere revealed by Longshot experiment, in The Geophysics of the Pacific Ocean Basin and Its Margin, Geophys. Monogr. Ser., ed. G. H. Sutton, M. H. Manghnani, and R. Moberly, Vol. 19, 480 pp., AGU, Washington, D.C., 1976.

ButLer, R., Anisotropic propagation of P- and S-waves in the western Pacific lithosphere, Geophys. J. R. Astron. Soc., 81, 89-101, 1985.

BUTLER, R., Regional seismic observations of the Ontong Java plateau and east Mariana basin, Mar. Geophys. Res., 8, 27-38, 1986.

BUtLer, R., C. MCCREery, L. Frazer, and D. WALKER, High-frequency seismic attenuation of oceanic P and S waves in the Western Pacific, J. Geophys. Res., 92, B2, 1383-1396, 1987.

Cessaro, R. and F. Duennebier, Regional earthquakes recorded by ocean bottom seismometers (OBS) and an ocean sub-bottom seismometer (OSS IV) on Leg 88, Initial Reports of the Deep Sea Drilling Project, 88, 129-145, 1987. 
Fuchs, K. and K. Schulz, Tunneling of low-frequency waves through the subcrustal lithosphere, J. Geophys., 42, 175-190, 1976.

GetTrust, J. and L. FraZer, A computer model study of the propagation of the long-range Pn phase, Geophys. Res. Lett., 8, 749-752, 1981.

HART, R. and F. Press, Sn velocities and the composition of the lithosphere in the regionalized Atlantic, J. Geophys. Res., 78, 407-411, 1973.

Mallick, S. and L. N. FraZer, Po/So synthetics for a variety of oceanic models, Eos Trans. $A G U, 67,1082,1986$.

MCCREERY, C. S., High-frequency Pn, Sn phases recorded by ocean bottom seismometers on the Cocos Plate, Geophys. Res. Lett., 8, 489-492, 1981.

MENKE, W. and P. RICHARDS, Crust-mantle whispering gallery phases: A deterministic model of teleseismic Pn wave propagation, J. Geophys. Res., 85, 5416-5422, 1980.

Nagumo, S., T. Ouchi, J. Kasahara, S. Koresawa, Y. Tomoda, K. Kobayashi, A. S. Furumoto, M. E. Odegard, and G. H. Sutton, Sub-moho seismic profile in the Mariana basin-ocean bottom seismograph long-range explosion experiment, Earth Planet. Sci. Lett., 53, 93-102, 1981.

OucHI, T., Spectral structure of high frequency $\mathrm{P}$ and $\mathrm{S}$ phases observed by OBS's in the Mariana Basin, J. Phys. Earth, 29, 305-326, 1981.

Ouchi, T., S. NAGumo, J. Kasahara, and S. Koresawa, Separation of high-frequency Pn phases in the mantle refracted $P$ phases at distances between $6^{\circ}$ and $18^{\circ}$ in the Western Pacific by ocean bottom seismograph array, Geophys. Res. Lett., 10, 1069-1072, 1983.

Sereno, T. and J. Orcutt, Synthesis of realistic oceanic Pn wave trains, J. Geophys. Res., 90 , 12755-12776, 1985.

Shimamura, H. and T. Asada, Apparent velocity measurements on an oceanic lithosphere, Phys. Earth Planet. Inter., 13, 15-22, 1976.

Shimamura, H., T. Asada, and M. Kumazawa, High shear velocity layer in the upper mantle of the Western Pacific, Nature, 269, 680-681, 1977.

STEPHENS, C. and B. IsACKS, Toward an understanding of Sn: Normal modes of Love waves in an oceanic structure, Bull. Seismol. Soc. Am., 67, 69-78, 1977.

Sutton, G. and D. HarveY, Complete synthetic seismograms to $2 \mathrm{~Hz}$ and $1,000 \mathrm{~km}$ for an oceanic lithosphere (abstract), EOS Trans. AGU, 62, 327, 1981.

Sutton, G., C. MCCreer Y, F. Duennebier, and D. Walker, Spectral analyses of highfrequency $\mathrm{Pn}, \mathrm{Sn}$ phases recorded on ocean bottom seismographs, Geophys. Res. Lett., 5 , 745-747, 1978.

Sutton, G., P. Pomeroy, J. Carter, and C. McCreery, Short period guided waves over oceanic and continental paths, DARPA Annual Program Review, 1983.

WALKER, D. A., High-frequency Pn phases observed in the Pacific at great distances, Science, 197, 257-259, 1977a.

Walker, D. A., High frequency Pn and Sn phases recorded in the Western Pacific, $J$. Geophys. Res., 82, 3350-3360, 1977 b.

WALKER, D., Oceanic $\mathrm{Pn} / \mathrm{Sn}$ phases: A qualitative explanation and reinterpretation of the TPhase, Hawaii Institute of Geophysics Report HIG-82-6, 19 pp., 1982.

WALKER, D., C. MCCREERY, and G. SUTTON, Spectral characteristics of high-frequency Pn, Sn phases in the western Pacific, J. Geophys. Res., 88, 4289-4298, 1983.

Walker, D., C. MCCreery, G. Sutton, and F. Duennebier, Spectral analyses of highfrequency Pn and Sn phases observed at great distances in the Western Pacific, Science, 199, 1333-1335, 1978. 